\title{
Bragg Reflections of Oblique Water Waves by Periodic Surface-Piercing and Submerged Breakwaters
}

\author{
I-Fan Tseng ${ }^{1}$, Chi-Shian You ${ }^{1}$ and Chia-Cheng Tsai ${ }^{1,2,3, * \mathbb{C}}$ \\ 1 Department of Marine Environment and Engineering, National Sun Yat-sen University, Kaohsiung 80424, \\ Taiwan; ifan@mail.nsysu.edu.tw (I.-F.T.); a0970926908@gmail.com (C.-S.Y.) \\ 2 Department of Marine Environmental Engineering, National Kaohsiung University of Science and \\ Technology, Kaohsiung 80778, Taiwan \\ 3 Center of Excellence for Ocean Engineering, National Taiwan Ocean University, Keelung 20224, Taiwan \\ * Correspondence: tsaichiacheng@nkust.edu.tw
}

Received: 2 June 2020; Accepted: 13 July 2020; Published: 16 July 2020

\begin{abstract}
The Bragg reflections of oblique water waves by periodic surface-piercing structures over periodic bottoms are investigated using the eigenfunction matching method (EMM). Based on the assumption of small wave amplitude, the linear wave theory is employed in the solution procedure. In the step approximation, the surface-piercing structures and the bottom profiles are sliced into shelves separated by abrupt steps. For each shelf, the solution is composed of eigenfunctions with unknown coefficients representing the wave amplitudes. Upon applying the conservations of mass and momentum, a system of linear equations is obtained and is then solved by a sparse-matrix solver. The proposed EMM is validated by several examples in the literature. Then, the method is applied to solve Bragg reflections of oblique water waves by various surface-piercing structures over periodic bottoms. From the numerical experiments, Bragg's law of oblique waves was used to predict the occurrences of Bragg resonance.
\end{abstract}

Keywords: eigenfunction matching method; oblique wave; Bragg reflection; step approximation; surface-piercing structure; periodic bottom

\section{Introduction}

When wind waves generated in the deep-water approach coastal regions, they experience various physical phenomena caused by inferences with structures, bathymetric variations, nonlinear wave interactions, etc. To prevent coasts from huge wave attacks, either floating or submerged breakwaters are usually installed in the coastal area. Although the nonlinear effects become significant as the waves approach the shoreline, consistent linear solutions are still valuable and provide extensive information concerning the wave impact on the nearshore and coastal environments. Furthermore, the linear solution usually serves as the starting point for a weakly nonlinear model [1].

Both submerged and floating breakwaters are typically designed in coastal regions. Submerged breakwaters are conventional structures that often rest on the sea floor. In addition, they are built as submerged types to satisfy the requirements of coastal landscapes and ecologies. Submerged breakwaters are heavy and large, and are designed by engineers for different purposes [2]. On the other hand, floating breakwaters have the advantage of lower construction costs compared to submerged breakwaters. Floating structures may be used in fishing farms for ecology conservation, tourism, and leisure. Moreover, they may be implemented at the ocean engineering working stations, such as oil exploration stations [3]. Engineers also use assembled floating structures to construct an airport on the sea [4], or to provide hospitable environments on the surface of the water. 
The Bragg reflection caused by the periodic breakwaters can help to effectively attenuate waves. For example, Mei et al. [5] considered using a series of submerged sinusoidal sandbars to protect the ocean platforms in Ekofisk of the North Sea, and Bailard et al. [6] found that the Bragg reflection of submerged bars can protect U.S. Gulf Coasts from storm-induced waves. In addition, Tsai and Wen [7] indicated that the Bragg reflections of submerged breakwaters were effective for protecting the Mi-Tuo Coast, Taiwan. The vortex generation and dissipation accompanying the Bragg scattering of water waves propagating over a series of submerged rectangular breakwaters were investigated by Hsu, et al. [8]. Recently, the Bragg reflections of floating breakwaters were studied by Ouyang et al. [9] and Ding et al. [10]. In this study, the combined Bragg reflections of periodic submerged and floating breakwaters are considered.

Numerical solutions are inevitable for solving water wave-scattering problems as analytic solutions are rare [11]. Berkhoff [12] derived the mild-slope equation (MSE) by integrating the governing equation over the vertical interval of water depth. Subsequently, the MSE was modified and improved in various studies $[13,14]$. In addition to the prescribed one-equation models, further improvements were made by including the evanescent modes, resulting in a system of hierarchical MSEs [15,16]. Athanassoulis and Belibassakis [17] additionally included a sloping-bottom mode to formulate the consistent coupled-mode system (CCMS), which has been applied to many water wave problems [18-20]. The MSE has been applied to solve problems of nonlinear waves [18,21], three dimensions [22], wave-current interactions [21,23], time evolutions [24], Bragg reflections [13], floating structures [25,26], etc. A comprehensive review can be found in a recent article [27].

Alternately, Takano [28] developed the eigenfunction marching method (EMM) for solving normal incident wave scattering over an elevated sill and a fixed surface obstacle. Subsequently, Kirby and his coauthors $[29,30]$ applied the EMM to solve problems of wave scattering over a trench of oblique incidences. For waves propagating over an arbitrary bottom profile, Devillard et al. [31], O'Hare and Davies [32,33], and Tsai et al. [34,35] decomposed the bottom profiles into a sequence of flat shelves separated by steps. The EMM has been applied to problems of viscous wave scattering [36-38], water wave scattering by tension-leg structures [39] and thin floating plates [40]. The accuracy of the EMM solutions was shown to be comparable with that of the MSE solutions [41]. In addition, the mathematical formulation is EMM is simpler as there are no requirements for the spatial derivatives of the eigenfunctions; however, they are needed in the MSE. However, the applications of EMM to three-dimensional, nonlinear, and/or time-dependent problems require further investigation.

In 1966, Katō, et al. [42] conducted laboratory experiments on the reflections of wave scattering using four simple floating structures, including a rectangular structure. Through numerical method, the diffraction of oblique waves scattering by a surface-piercing rectangular structure was studied by Bai [43]. Sequentially, Kanoria et al. [44] derived analytical solutions for normally incident wave scattering by a surface-piercing rectangular structure in water of uniform finite depth. The analytical solutions were then extended to oblique waves by Söylemez and Gören [45]. For an arbitrary cross-section, Garrison [46] developed a Green's function procedure to compute oblique wave scattering. Using numerical methods, Ouyang et al. [9] recently studied the Bragg reflections of normal waves by fixed rectangular structures. Ding et al. [10] studied the Bragg reflections of normal waves by structures of different shapes using the boundary element method. All the prescribed studies consider scattering problems with different configurations of various structures over a flat bottom.

Manisha et al. [47] recently developed a model considering the effects of bottom undulations for oblique wave interaction with a surface-piercing rectangular structure behind a submerged breakwater or a trench. They connected the solutions of the MSE and EMM for the regions of the undulated bottom and rectangular structure over the flat bottom, respectively. In this study, the EMM model is developed for analyzing the combined phenomena of oblique incidence, surface-piercing structures of different shapes, Bragg reflections, and undulated bottoms. In the solution procedure, the surface-piercing structures and bottom topography are sliced into successive flat shelves separated by abrupt steps. The matching conditions of the normal flow flux and the continuity of pressure are imposed on the 
interface boundaries. The EMM model is validated by comparisons with analytical solutions in the literature $[10,45,47]$.

Bragg's law is usually used to predict the wavelengths at which the X-rays are intensively reflected by crystalline solids [48]. For water-wave problems, Bragg's law is applied for scatterings by floating $[9,10]$ and submerged $[5-7,23]$ structures at normal incidence. For oblique incidence, Mei [49] and Dalrymple et al. [50] applied Bragg's law for water wave scattering by bottom ripples. In this study, numerical experiments were conducted to study the Bragg reflections by the combined effects of floating structures, bottom variations, and oblique incidence. In addition, the numerical results are compared with those predicted by Bragg's law.

This paper is organized as follows: the wave problem is mathematically modeled and the EMM solution is developed in Section 2, and the EMM model is validated in Section 3. Discussions on oblique Bragg reflections by surface-piercing and submerged breakwaters are provided in Section 4 . Finally, conclusions are presented in Section 5.

\section{Materials and Methods}

\subsection{The Mathematical Model}

We consider the problem of oblique monochromatic water wave scattering by surface-piercing structures over uneven bottoms. The wave amplitude is assumed to be small enough that the linear wave theory is applicable. The wave motion is assumed to be time-harmonic, $e^{-\mathbf{i} \sigma t}$, where $\sigma=2 \pi / T$ is the angular frequency, $T$ is the wave period, $t$ is the time, and $\mathbf{i}$ is the unit of complex numbers. Figure 1 shows a schematic representation of the wave scattering problem induced by a surface-piercing structure over uneven bottoms. In the figure, the surface-piercing structures and sea bottom are discretized into a series of $M$ shelves in the intervals of $x_{m-1} \leq x \leq x_{m}$ for $m=1,2,3 \ldots, M$, with a water depth $h_{m}>d_{m}$, where $d_{m}>0$ is the submergence depth of the structure. Alternatively, $d_{m}=0$ is designated if there is no structure in the interval. Furthermore, $x_{0}=-\infty$ and $x_{M}=\infty$ are assumed.

Considering the solution on the $m$-th shelf in the interval $x_{m-1} \leq x \leq x_{m}$, the velocity of the fluid is defined by

$$
\mathbf{u}_{m}=\nabla \phi_{m},
$$

where $\nabla=(\partial / \partial x, \partial / \partial y, \partial / \partial z)$ is the three-dimensional del operator with respect to the three-dimensional Cartesian coordinates $(x, y, z)$ and $\phi_{m}$ is the velocity potential. According to the linear wave theory, the velocity potential is governed by the Laplace equation as

$$
\nabla^{2} \phi_{m}=0
$$

It should be noted that $\phi_{m}$ is only related to the spatial part of the velocity potential for the remainder of this work. If there is no structure in the interval $\left(d_{m}=0\right)$, the problem is subjected to the kinematic and dynamic free-surface boundary conditions, respectively, as

$$
-\mathbf{i} \sigma \eta_{m}-\frac{\partial \phi_{m}}{\partial z}=0
$$

and

$$
-\mathbf{i} \sigma \phi_{m}+g \eta_{m}=0 \text { on } z=0 .
$$

Equations (3) and (4) can be combined to obtain

$$
\frac{\partial \phi_{m}}{\partial z}-\frac{\sigma^{2}}{g} \phi_{m}=0 \text { on } z=0 .
$$


On the other hand, if there is a structure in the interval $\left(d_{m}>0\right)$, the boundary condition on the bottom of the surface-piercing structure is given by

$$
\frac{\partial \phi_{m}}{\partial z}=0 \text { on } z=-d_{m}
$$

In addition, the boundary condition on the sea bottom can be expressed in the form of

$$
\frac{\partial \phi_{m}}{\partial z}=0 \text { on } z=-h_{m}
$$

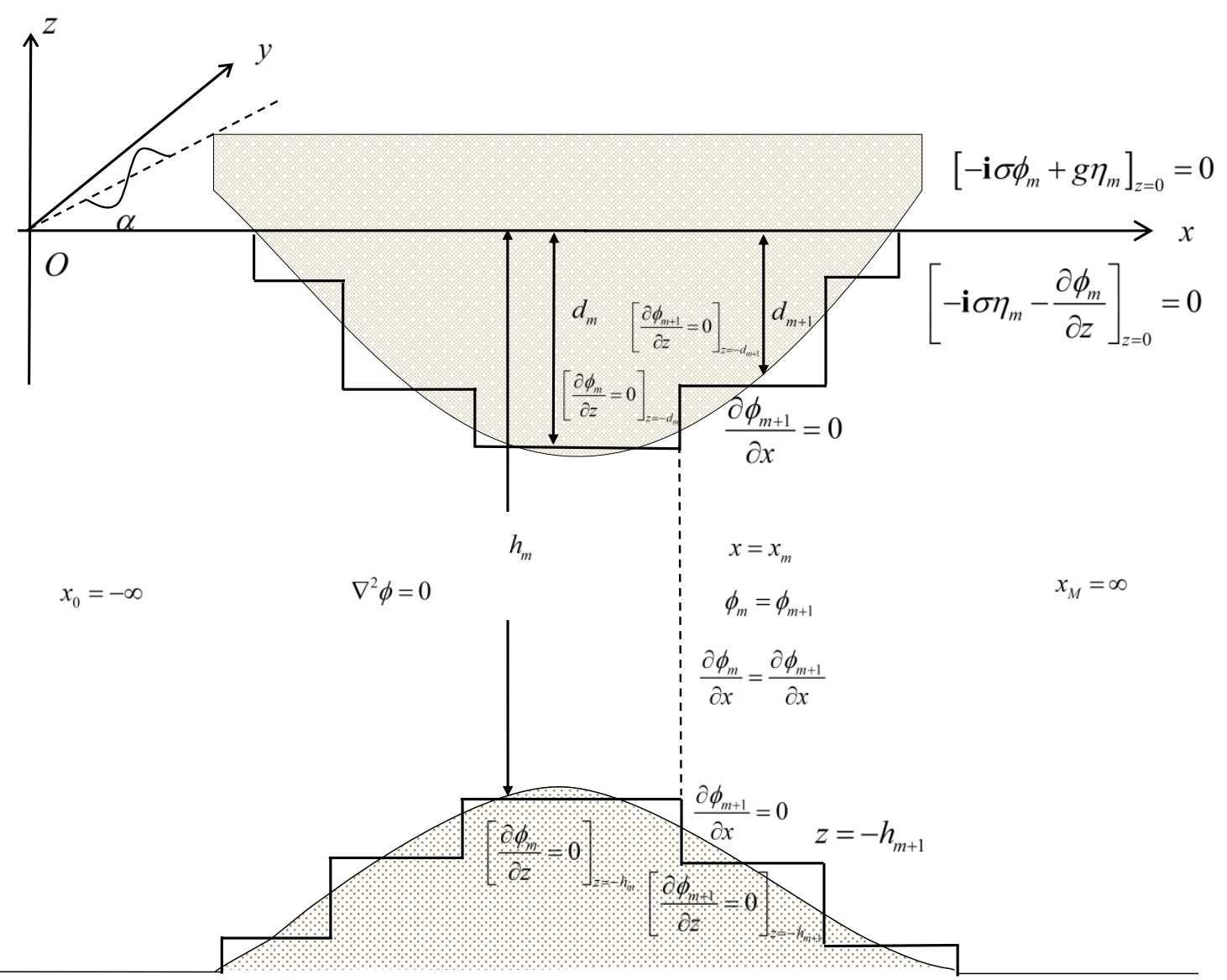

Figure 1. Schematic representation of the boundary-value problem of water-wave-scattering by the surface-piercing structure over even bottom. The study domain divided into different regions with $M$ shelves separated by $M-1$ steps.

Equations (2)-(7) are sufficient to construct the complete solution by eigenfunctions and will be given in the next section.

Then, connection conditions are required to match the solutions $\phi_{m}$ and $\phi_{m+1}$ as

$$
\phi_{m}=\phi_{m+1}
$$

and

$$
\frac{\partial \phi_{m}}{\partial x}=\frac{\partial \phi_{m+1}}{\partial x}
$$


on $-d_{m}^{\max }<z<-h_{m}^{\min }$ and $x=x_{m}$ with $d_{m}^{\max }=\max \left(d_{m}, d_{m+1}\right)$ and $h_{m}^{\min }=\min \left(h_{m}, h_{m+1}\right)$. In addition, no-penetration conditions are needed on the bottom and structure side-walls, respectively, as

$$
\frac{\partial \phi}{\partial x}=0 \text { on }-h_{m}^{\max }<z<-h_{m}^{\min } \text { and } x=x_{m}
$$

and

$$
\frac{\partial \phi}{\partial x}=0 \text { on }-d_{m}^{\max }<z<-d_{m}^{\min } \text { and } x=x_{m} .
$$

The definitions of $h_{m}^{\max }$ and $d_{m}^{\min }$ are similar, and thus neglected here. In Equations (10) and (11), $\phi$ stands for either $\phi_{m}$ or $\phi_{m+1}$ depending on the water side of the wall.

Then, considering a monochromatic wave train with incidence angle $\alpha$, amplitude $a$, frequency $\sigma$, and wavelength $\lambda$, which propagates towards the surface-piercing structures over an uneven bottom. Therefore to make the solution unique, the following far-field conditions are required

$$
\eta=a\left(e^{\mathbf{i} \hat{k}_{1,0} x}+K_{R} e^{i \theta_{R}} e^{-\mathbf{i} \hat{k}_{1,0} x}\right) e^{i k_{y} y} \text { as } x \rightarrow-\infty
$$

and

$$
\eta=a K_{T} e^{\mathbf{i} \theta_{T}} e^{\mathbf{i} \hat{k}_{M, 0} x} e^{\mathbf{i} k_{y} y} \text { as } x \rightarrow \infty .
$$

where $K_{R}, \theta_{R}, K_{T}$, and $\theta_{T}$ are real numbers, such that $K_{R} e^{\mathbf{i} \theta_{R}}$ and $K_{T} e^{\mathbf{i} \theta_{T}}$ are the reflection and transmission coefficients, respectively. In Equations (12) and (13), $\hat{k}_{1,0}, \hat{k}_{M, 0}$, and $k_{y}$ are positive real wavenumbers defined by

$$
\hat{k}_{m, n}=\sqrt{k_{m, n}^{2}-k_{y}^{2}},
$$

and

$$
k_{y}=k_{1,0} \sin \alpha .
$$

where $k_{1,0}=2 \pi / \lambda>0$ and $k_{M, 0}>0$ are the progressive wavenumbers obtained from the dispersion relation

$$
\frac{\sigma^{2}}{g}=k_{m, 0} \tanh k_{m, 0} h_{m} .
$$

Here, it is assumed that there is no structure over the first and last shelves, i.e., $d_{1}=0$ and $d_{M}=0$.

Now, the problem is well-defined, and the estimation of the reflection and transmission coefficients are presented in the next subsection.

\subsection{Eigenfunction Matching Method}

To construct the complete solution using eigenfunctions, a complete set of wavenumbers is required. When there is no structure on a shelf $\left(d_{m}=0\right)$, in addition to the progressive wavenumber $k_{m, 0}$ in Equation (16) the evanescent wavenumbers $k_{m, n}(n=1,2,3, \ldots)$ are defined by

$$
k_{m, n}=\mathbf{i} \kappa_{m, n},
$$

where $\kappa_{m, n}$ is the $n$-th smallest positive root of the dispersion relation

$$
\frac{\sigma^{2}}{g}=-\kappa_{m, n} \tan \kappa_{m, n} h_{m} .
$$

and when there is a structure over a shelf $\left(d_{m}>0\right)$, the wavenumber is alternatively defined as

$$
k_{m, n}=\frac{\mathbf{i} n \pi}{h_{m}-d_{m}}
$$


for $n=0,1,2, \ldots$. As the incident wave is oblique, we have to define the $\mathrm{x}$-component of the wavenumber $\hat{k}_{m, n}$ by Equation (14). The complex-valued wavenumbers, $k_{m, n}$ and $\hat{k}_{m, n}$, defined in Equations (14)-(19), enable the formulation of a unified EMM for all types of situations $\left(d_{m}=0\right.$ or $d_{m}>0 ; n=0$ or $\left.\mathrm{n}>0\right)$.

Based on the linear wave theory, the complete solution of the velocity potential for the $m$-th shelf may be expressed as

$$
\phi_{m}(x, y, z)=\sum_{n=0}^{N}\left(A_{m, n} \xi_{m, n}^{(1)}(x)+B_{m, n} \xi_{m, n}^{(2)}(x)\right) \zeta_{m, n}(z) e^{\mathrm{i} k_{y} y}
$$

for $m=1,2,3, \ldots, M$, where $A_{m, n}$ and $B_{m, n}$ are unknown coefficients to be determined. Upon applying the conditions in Equations (2), (5)-(7) and by employing the method of the separation of variables, the eigenfunctions, $\zeta_{m, n}(z), \xi_{m, n}^{(1)}(x)$, and $\xi_{m, n}^{(2)}(x)$, can be obtained and expressed as

$$
\begin{gathered}
\zeta_{m, n}(z)=\cosh k_{m, n}\left(h_{m}+z\right), \\
\xi_{m, n}^{(1)}(x)=\left\{\begin{array}{cc}
e^{\mathbf{i} \hat{k}_{m, n}\left(x-\bar{x}_{m-1}\right)} & \hat{k}_{m, n} \neq 0 \\
1 & \hat{k}_{m, n}=0
\end{array}\right.
\end{gathered}
$$

and

$$
\xi_{m, n}^{(2)}(x)=\left\{\begin{array}{cc}
e^{-\mathbf{i} \hat{k}_{m, n}\left(x-\bar{x}_{m}\right)} & \hat{k}_{m, n} \neq 0 \\
x & \hat{k}_{m, n}=0
\end{array}\right.
$$

with

$$
\left\{\begin{array}{l}
\bar{x}_{m}=x_{m} \text { for } m=1,2, \ldots, M-1 \\
\bar{x}_{0}=\bar{x}_{M}=0 .
\end{array}\right.
$$

By observing at Equation (21), we have $\zeta_{m, n}=1$ for $k_{m, n}=0$. According to the Sturm-Liouville theory [51], the following orthogonal relation is used for solving the problem

$$
\left\langle\zeta_{m, n} \mid \zeta_{m, l}\right\rangle=\Lambda_{m, n} \delta_{n l}
$$

where $n$ and $l$ is a mode index varying from 0 to $N, \delta_{n l}$ is the Kronecker delta function, and $\Lambda_{n}$ is a function of $h_{m}$ and $k_{m, n}$, written as

$$
\Lambda_{m, n}=\frac{2 k_{m, n}\left(h_{m}-d_{m}\right)+\sinh 2 k_{m, n}\left(h_{m}-d_{m}\right)}{4 k_{m, n}}
$$

For convenience, we define the inner product of two depth eigenfunctions as follows.

$$
\langle F \mid G\rangle=\int_{-\lambda_{2}}^{-\lambda_{1}} F(z) G(z) d z
$$

where $F$ and $G$ are the depth eigenfunctions of $\zeta_{m, n}$ with arbitrary $m$ and $n$; and $\lambda_{1}$ and $\lambda_{2}$ represent the structure submergence and water depths, respectively, which correspond to the first depth eigenfunction F.

It should be noted that the eigenfunction definitions of $\zeta_{m, n}(z), \xi_{m, n}^{(1)}(x)$, and $\xi_{m, n}^{(2)}(x)$ are valid for all cases $\left(d_{m}=0\right.$ or $d_{m}>0 ; n=0$ or $\left.n>0\right)$ if the complex-valued wavenumbers, $k_{m, n}$ and $\hat{k}_{m, n}$, are defined by Equations (14)-(19).

Based on the far-field conditions (Equations (12) and (13)) and the dynamic free-surface boundary condition (Equation (4)), the far-field solutions of the velocity potential can be expressed as

$$
\phi_{1}=-\frac{\mathbf{i} a g}{\sigma} \frac{\cosh k_{1,0}\left(h_{1}+z\right)}{\cosh k_{1,0} h_{1}}\left(e^{\mathbf{i} \hat{k}_{1,0} x}+K_{R} e^{\mathbf{i} \theta_{R}} e^{-\mathbf{i} \hat{k}_{1,0} x}\right) e^{\mathbf{i} k_{y} y} \text { as } x \rightarrow-\infty
$$


and

$$
\phi_{M}=-\frac{\mathbf{i} a g}{\sigma} \frac{\cosh k_{M, 0}\left(h_{M}+z\right)}{\cosh k_{M, 0} h_{M}}\left(K_{T} e^{\mathrm{i} \theta_{T}} e^{\mathrm{i} \hat{k}_{M, 0} x}\right) e^{\mathrm{i} k_{y} y} \text { as } x \rightarrow \infty .
$$

Comparing Equations (20), (28), and (29), the following equations can be obtained as

$$
\begin{gathered}
A_{1,0}=-\frac{\mathbf{i} a g}{\sigma} \frac{1}{\cosh k_{1,0} h_{1}}, \\
B_{1,0} e^{\mathrm{i} \hat{k}_{m, n} \bar{x}}=-\frac{\mathbf{i} a K_{R} e^{\mathbf{i} \theta_{R} g}}{\sigma} \frac{1}{\cosh k_{1,0} h_{1}}, \\
A_{M, 0} e^{-\mathbf{i} \hat{k}_{M, 0} \bar{x}_{M-1}}=-\frac{\mathbf{i} a K_{T} e^{\mathbf{i} \theta_{T} g}}{\sigma} \frac{1}{\cosh k_{M, 0} h_{M}}, \\
A_{1, n}=0 \text { for } n=1,2, \ldots, N,
\end{gathered}
$$

and

$$
B_{M, n}=0 \text { for } n=0,1, \ldots, N \text {. }
$$

The other coefficients $A_{m, n}$ and $B_{m, n}$ in Equation (20) can be determined using the matching conditions, Equations (8)-(11), at two adjacent shelves. The conservation of momentum, stemming from Equation (8), gives

$$
\left.\left\langle\zeta_{m, l}^{\text {inner }} \mid \phi_{m}\right\rangle\right|_{x=x_{m}}=\left.\left\langle\zeta_{m+1, l}^{\text {inner }} \mid \phi_{m+1}\right\rangle\right|_{x=x_{m}},
$$

where $\zeta_{m, l}^{\text {inner }}(z)$ is the inner depth eigenfunction corresponding to $d_{m}^{\max }$ and $h_{m}^{\min }$. For clarity, $\zeta_{m, l}^{\text {inner }}(z)$ is defined by Equation (21) with the wavenumbers $k_{m, n}$ obtained from Equations (16)-(19) as $d_{m}$ and $h_{m}$ replaced by $d_{m}^{\max }$ and $h_{m}^{\min }$, respectively. Similarly, the conservation of mass, comes from Equations (9)-(11), yields the following equation

$$
\left.\left\langle\frac{\partial \phi_{m}}{\partial x} \mid \zeta_{m, l}^{\text {outer }}\right\rangle\right|_{x=x_{m}}=\left.\left\langle\frac{\partial \phi_{m+1}}{\partial x} \mid \zeta_{m, l}^{\text {outer }}\right\rangle\right|_{x=x_{m}},
$$

where $\zeta_{m, l}^{\text {outer }}(z)$ is the outer depth function corresponding to $d_{m}^{\min }$ and $h_{m}^{\max }$. In Equations (35) and (36), the subscripted indices go as $l=0,1, \ldots, N$ and $m=1,2, \ldots, M-1$. Additionally, it should be noted that Equations (35) and (36) are valid for all eight cases, as shown in Figure 2.

By using Equation (20), Equations (35) and (36) can be rewritten in the following forms

$$
\begin{aligned}
& \sum_{n=0}^{N}\left(A_{m, n} \xi_{m, n}^{(1)}\left(x_{m}\right)+B_{m, n} \xi_{m, n}^{(2)}\left(x_{m}\right)\right)\left\langle\zeta_{m, l}^{\text {inner }} \mid \zeta_{m, n}\right\rangle \\
& =\sum_{n=0}^{N}\left(A_{m+1, n} \xi_{m+1, n}^{(1)}\left(x_{m}\right)+B_{m+1, n} \xi_{m+1, n}^{(2)}\left(x_{m}\right)\right)\left\langle\zeta_{m, l}^{\text {inner }} \mid \zeta_{m+1, n}\right\rangle
\end{aligned}
$$

and

$$
\begin{aligned}
& \sum_{n=0}^{N}\left(A_{m, n} \frac{d \xi_{m, n}^{(1)}}{d x}\left(x_{m}\right)+B_{m, n} \frac{d \xi_{m, n}^{(2)}}{d x}\left(x_{m}\right)\right)\left\langle\zeta_{m, n} \mid \zeta_{m, l}^{\text {outer }}\right\rangle \\
& =\sum_{n=0}^{N}\left(A_{m+1, n} \frac{d \xi_{m+1, n}^{(1)}}{d x}\left(x_{m}\right)+B_{m+1, n} \frac{d \xi_{m+1, n}^{(2)}}{d x}\left(x_{m}\right)\right)\left\langle\zeta_{m+1, n} \mid \zeta_{m, l}^{\text {outer }}\right\rangle .
\end{aligned}
$$

Subsequently, it can be found that Equations (30), (33), (34), (37), and (38) are $2 M(N+1)$ linear equations, that can be used to solve the $2 M(N+1)$ unknowns, $A_{m, n}$ and $B_{m, n}$. Furthermore, Equations (37) and (38) can be reduced to the original equations of EMM for normal water-wave-scattering without structures where $\alpha=0$ and $d_{m}=0$ [28,35]. In this study, the SuperLU is used to solve the resulting sparse system of linear equations [52]. After the unknowns, $A_{m, n}$ and $B_{m, n}$, are solved, the reflection and transmission coefficients can be obtained by Equations (31) and (32), respectively. This completes the solution procedure for the EMM. 


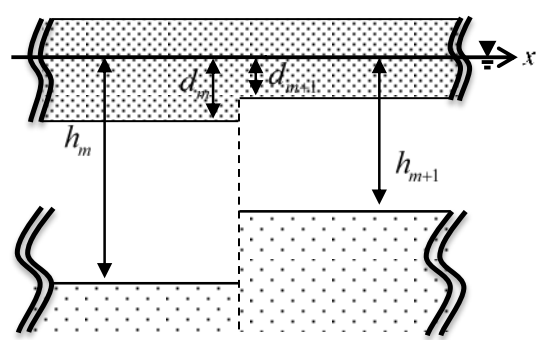

(a)

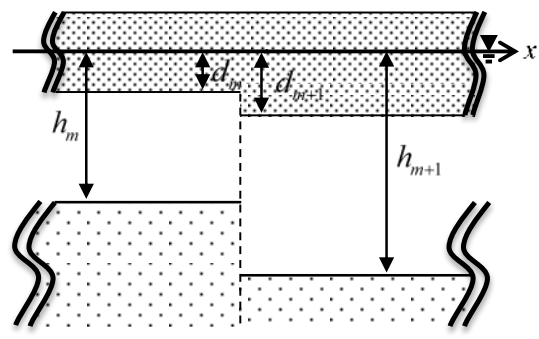

(c)

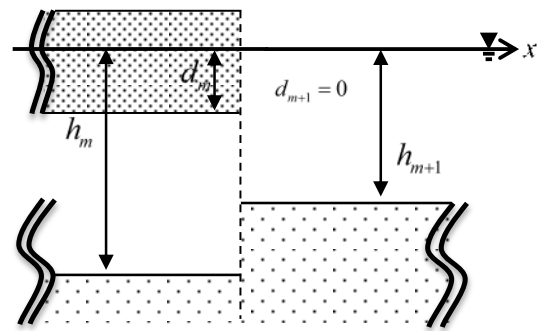

(e)

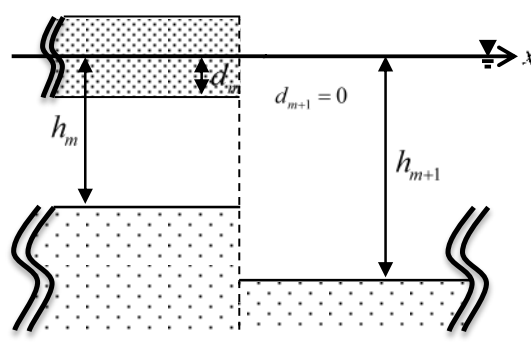

(g)

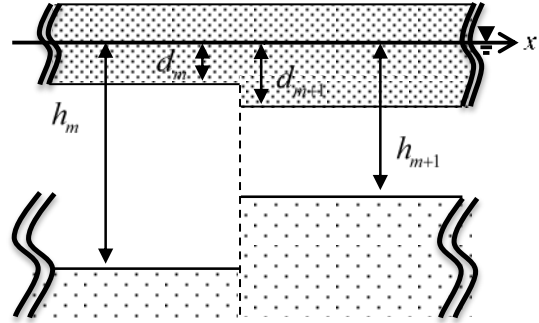

(b)

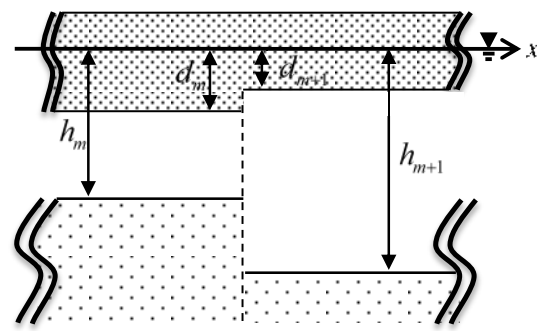

(d)

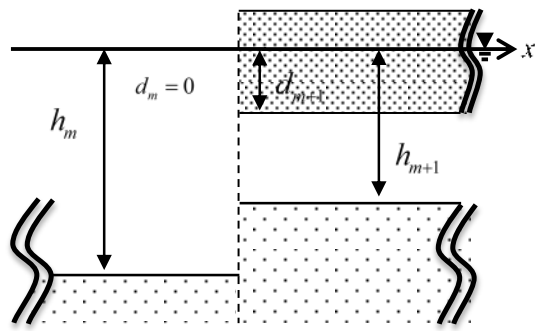

(f)

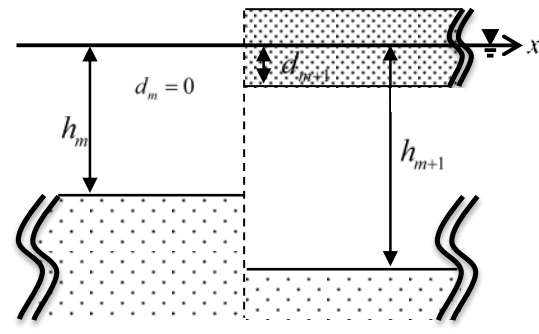

(h)

Figure 2. Schematics for eight different situations of shelves separated by abrupt connections.

\section{Results}

The present model is validated using three numerical examples.

\subsection{Rectangular Surface-Piercing Structure over a Flat Bottom}

First, we consider monochromatic wave trains with incidence angles $\alpha=45^{\circ}$ and $\alpha=75^{\circ}$, which propagate towards a rectangular surface-piercing structure over a flat bottom with water depth $h=1 \mathrm{~m}$, as depicted in Figure 3. The breadth and depth of the rectangular barrier are set to $2 a=0.6 \mathrm{~m}$ and $d=0.2 \mathrm{~m}$, respectively. Figure 4 shows a comparison of the reflection and transmission coefficients obtained by the proposed EMM with the results obtained by Lebreton and Margnac [53], Bai [43], Söylemez and Gören [45]. In the figure, the convergence with respect to the increasing numbers of evanescent modes, $N$, is obvious. Both the reflection and transmission coefficients evaluated by the present model with $N=5$ are in good agreement with those in the literature for the whole 
frequency range. This validates the present model for solving problems of oblique wave scattering by a rectangular surface-piercing structure over a flat bottom.

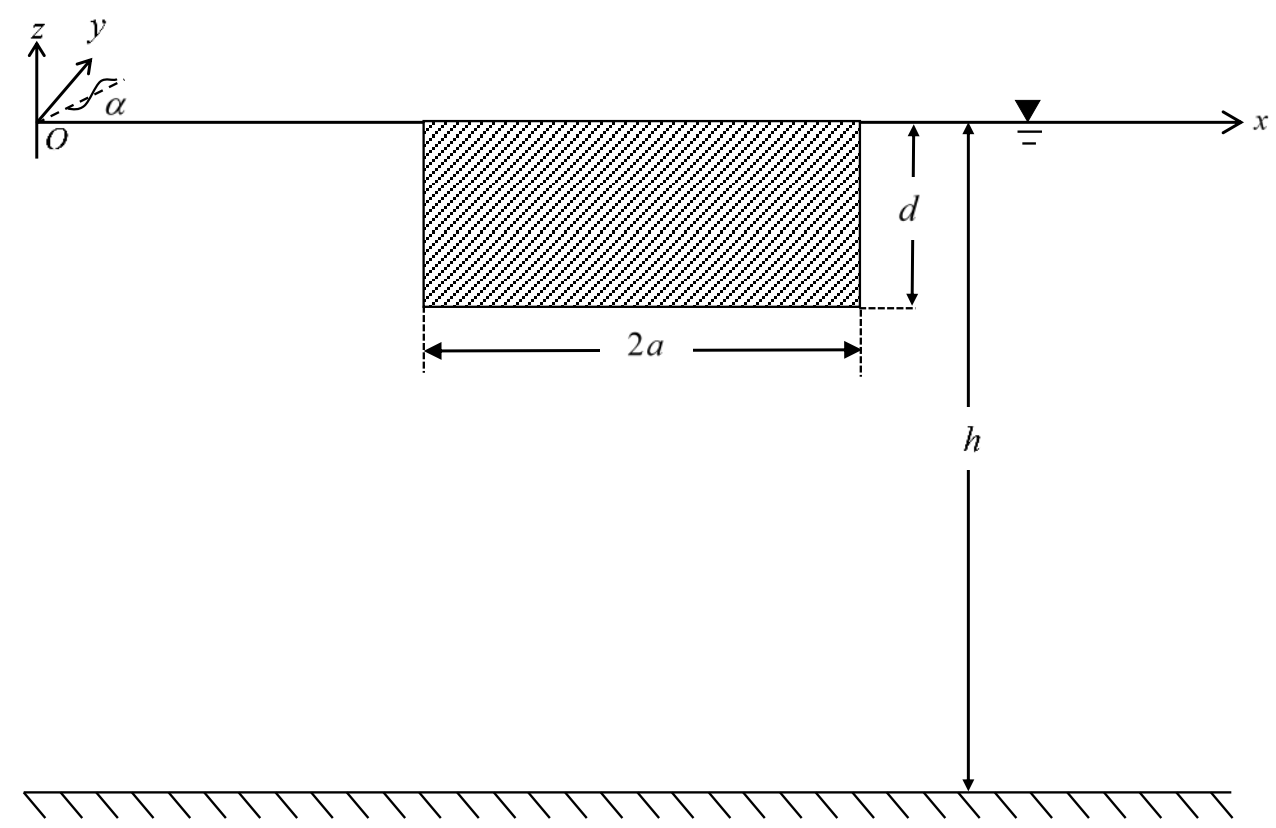

Figure 3. Schematic representation of the water wave scattering by a rectangular surface-piercing structure over flat bottom.

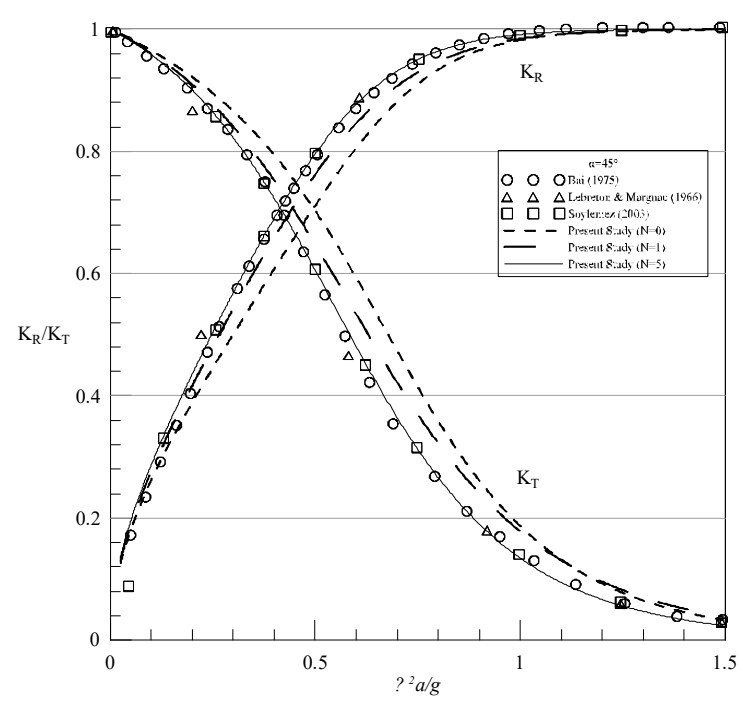

(a)

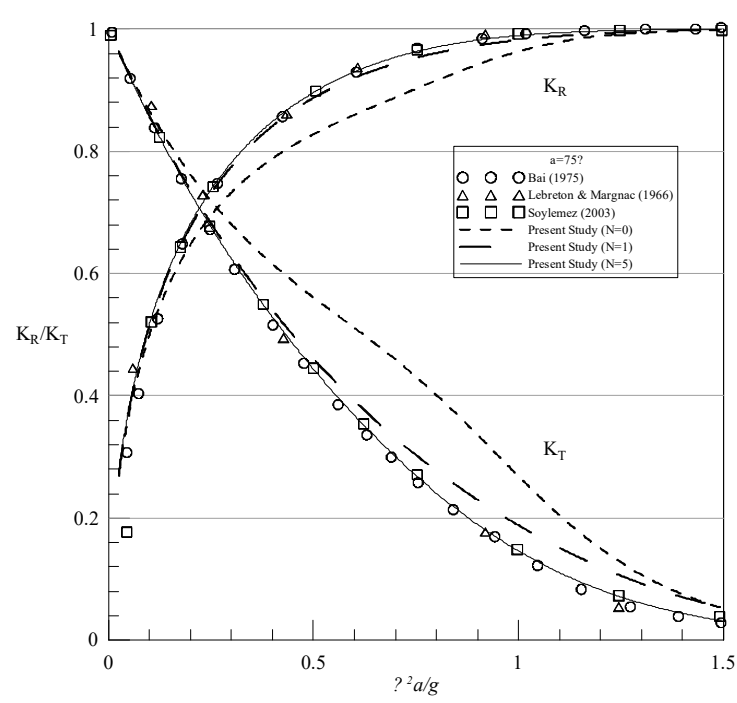

(b)

Figure 4. Comparison of the reflection and transmission coefficients from the present study with the results in the literatures for water wave scattering by a rectangular surface-piercing structure over flat bottom with incidence angles (a) $\alpha=45^{\circ}$ and (b) $\alpha=75^{\circ}$.

\subsection{Rectangular Surface-Piercing Structure behind Parabolic Breakwater}

We now consider oblique monochromatic wave trains that propagate towards a rectangular surface-piercing structure behind a parabolic breakwater defined by $z=-h(x)$ for $|x| \leq c$ as

$$
h(x)=\left(h-h_{b}\right)\left(1+\frac{h_{b} x^{2}}{\left(h-h_{b}\right) c^{2}}\right) .
$$


As shown in Figure 5, the other parameters are set as $h_{1}=30 \mathrm{~m}, h_{b}=15 \mathrm{~m}, d=7.5 \mathrm{~m}, 2 c=200 \mathrm{~m}$, $w=20 \mathrm{~m}$, and $2 a=30 \mathrm{~m}$, which are exactly the same values as those of Manisha et al. [47]. Furthermore, 40 shelves are used to approximate the parabolic breakwater after performing a preliminary convergence analysis as shown in Figure 6.

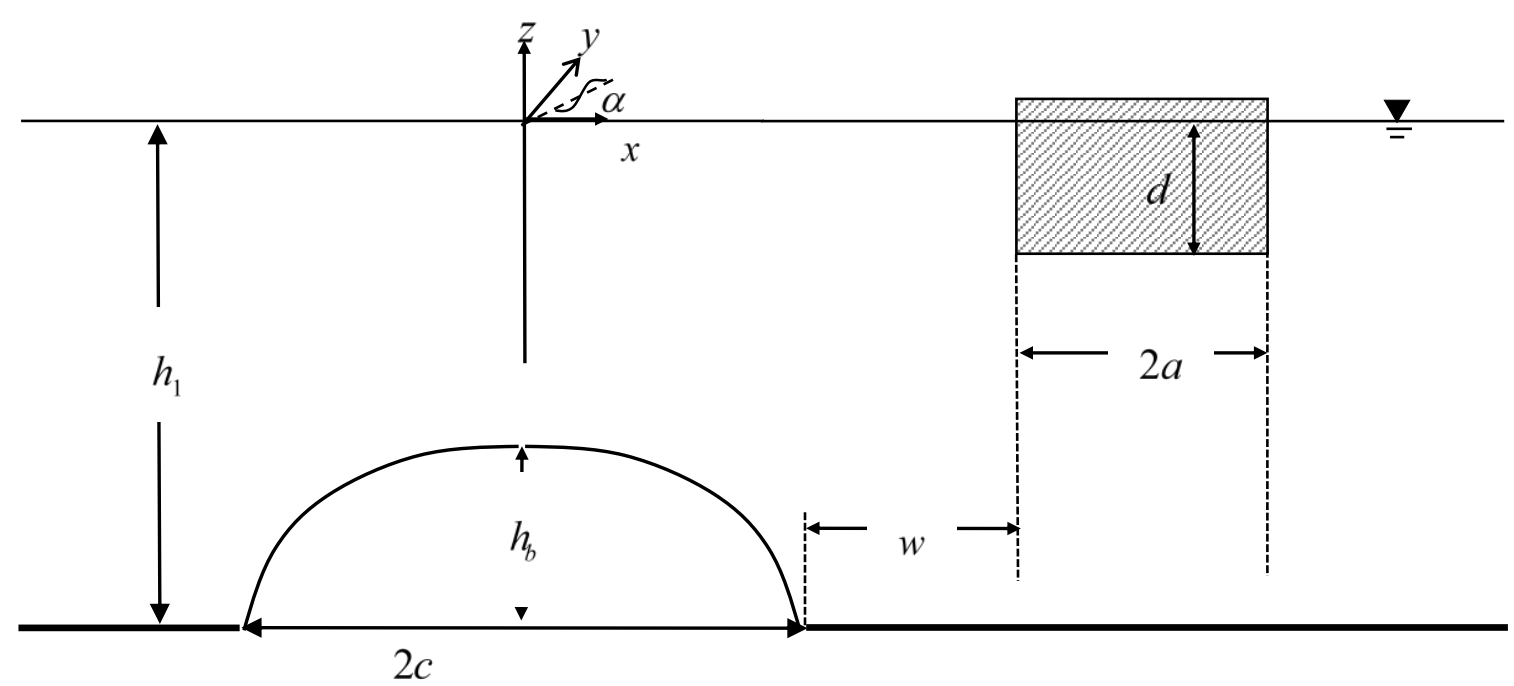

Figure 5. Schematic diagram of the water-wave-scattering by a rectangular surface-piercing structure behind a parabolic breakwater.

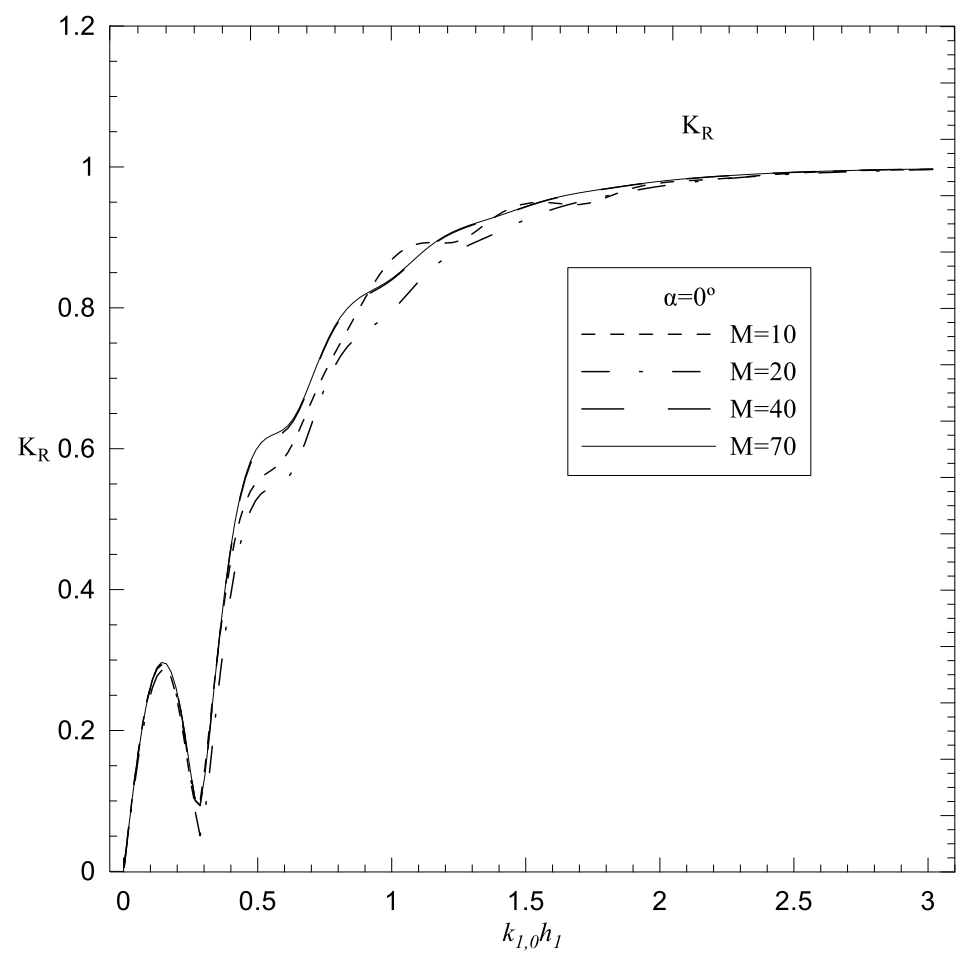

Figure 6. Convergence analysis of $M$ for the water wave scattering by a rectangular structure behind a parabolic breakwater.

Figure 7 shows the comparison of reflection coefficients obtained by the present method and those from Manisha et al. [47]. In the figure, the convergence with respect to the increasing numbers of evanescent modes, $N$, can also be observed. The convergent results of the present model are in good agreement with those in Manisha et al. [47]. This validates the proposed EMM for solving oblique wave scattering by a rectangular surface-piercing structure over uneven bottoms. 


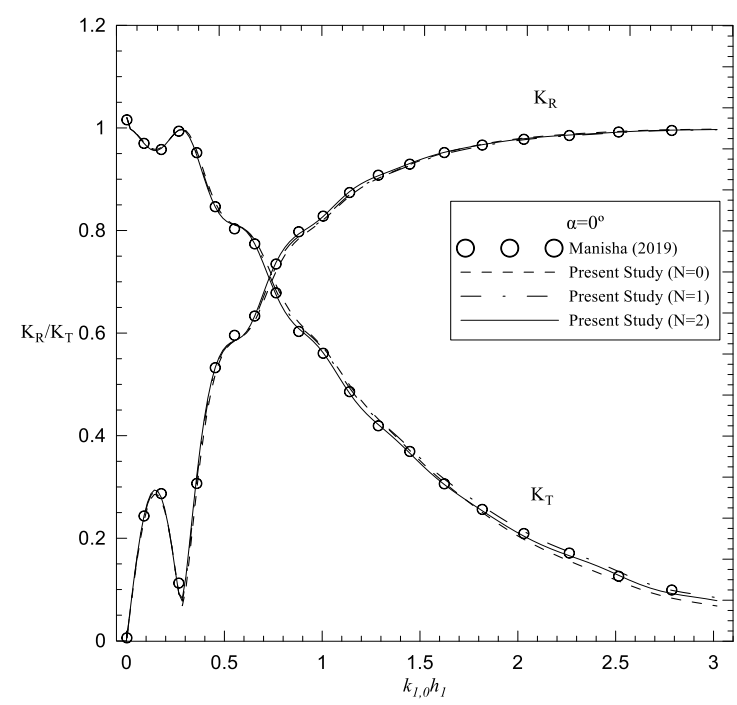

(a)

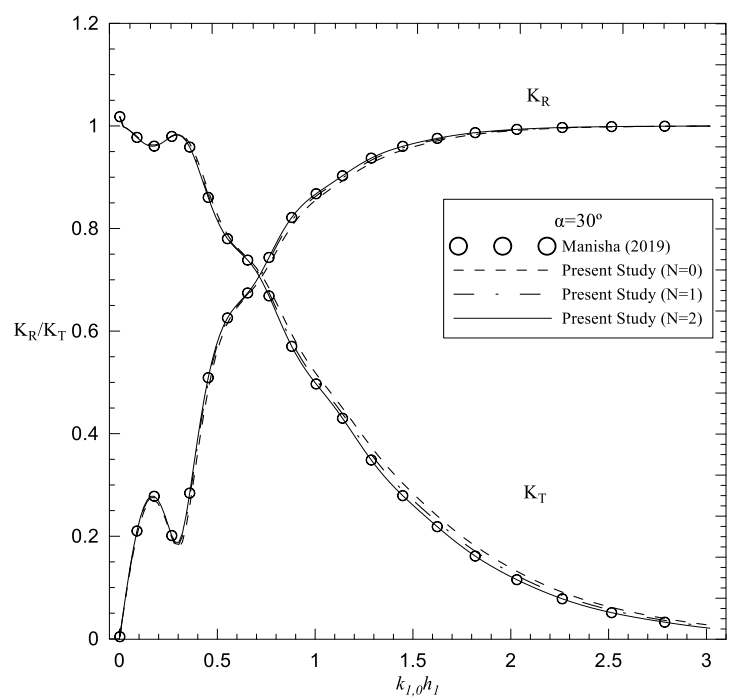

(b)

Figure 7. Comparison of the reflection coefficients from the present study with the results from the literature for the (a) normal and (b) oblique water-wave-scattering by a rectangular structure behind a parabolic breakwater.

\subsection{Bragg Reflections by Periodic Surface-Piercing Structures over Flat Bottom}

As the final example of validation, we consider normal monochromatic wave trains, which propagate towards a series of periodic rectangular and triangular surface-piercing structures over flat bottoms with water depth $h=1 \mathrm{~m}$. As depicted in Figure 8, the other parameters are set as $\alpha=0$, $L=3, d / h=0.25, a / h=0.25$, and $S / h=3$, which are exactly the same values as those of Ding et al. [10]. Typically, 10 shelves are adopted to approximate each triangular structure in this example, as shown in Figure 9b.

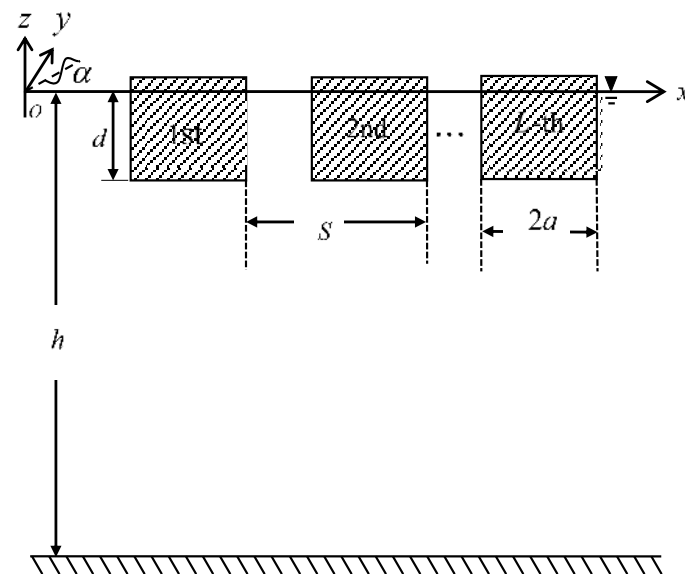

(a)

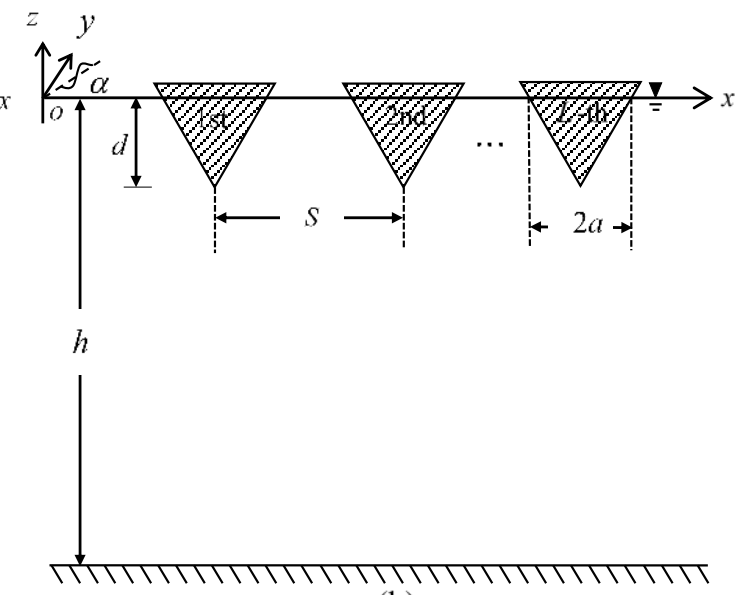

(b)

Figure 8. Schematic diagram of Bragg reflections by periodic (a) rectangular and (b) triangular surface-piercing structures over flat bottom. 


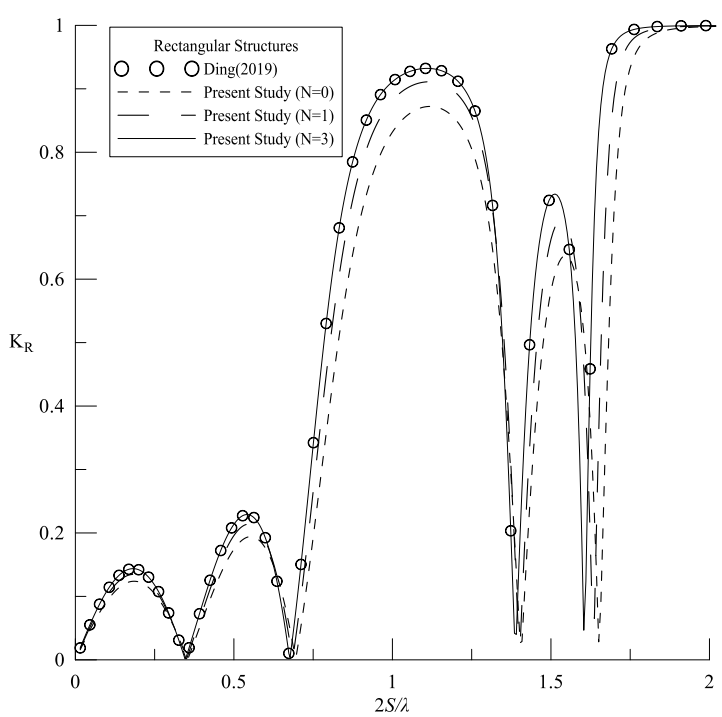

(a)

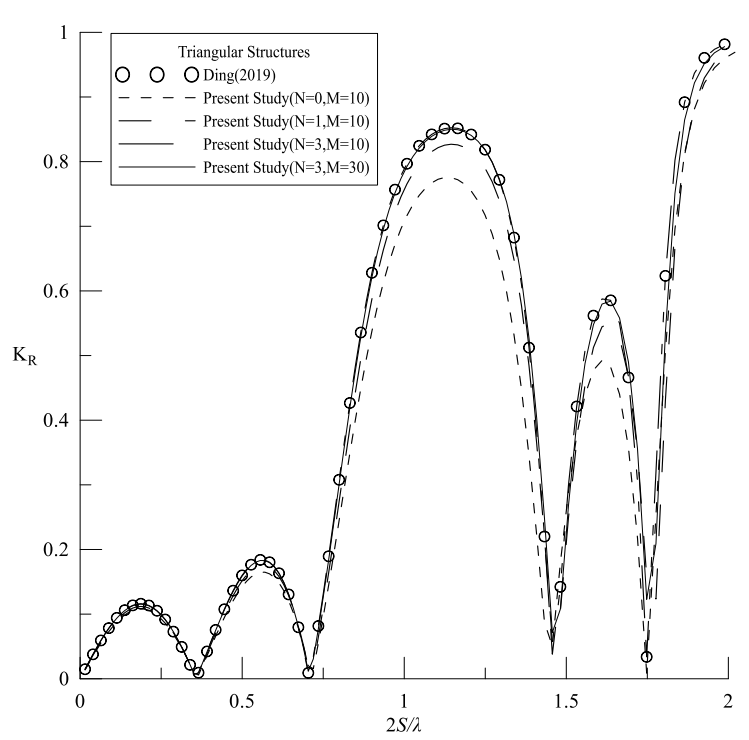

(b)

Figure 9. Comparison of the reflection coefficients from the present study with the results in the literature for Bragg reflections by periodic (a) rectangular and (b) triangular surface-piercing structures over flat bottom.

Figure 9 shows the comparison of the reflection coefficients obtained by the present method and Ding et al. [10]. In the figure, the convergence with respect to the increasing numbers of evanescent modes, $N$, is also obvious, and the results by the present model with $N=3$ are in good agreement with those obtained by Ding et al. [10]. In addition, Bragg's law confirms that intensive reflections occur for $2 S / \lambda$, being positive integers. This validates the present model for solving Bragg reflections of normal water waves by periodic surface-piercing structures of arbitrary shapes over flat bottoms.

\section{Discussion}

After the model is validated, the proposed EMM model is applied to solve Bragg reflections of oblique water waves by periodic rectangular and triangular surface-piercing structures over periodic parabolic breakwaters as depicted in Figure 10. The parabolic breakwaters are defined by Equation (39) with $h_{1}=1 \mathrm{~m}$ and $2 c=0.5 \mathrm{~m}$ and the surface-piercing structures are either rectangular or triangular with $2 a=0.5 \mathrm{~m}$ and $d=0.25 \mathrm{~m}$, as shown in Figure 8. In addition, $S=3 \mathrm{~m}$ is set such that the problem configuration is reduced to the previous example if $h_{b}=0$. The incidence angle $\alpha$, structure or breakwater number $L$, and breakwater height $h_{b}$ are the parameters studied in the following.

As depicted in Figure 11, we extend the previous example by considering waves of different incidence angles $\alpha=15^{\circ}$ and $\alpha=30^{\circ}$. In other words, we set $N=3$ and $h_{b}=0$, and used 10 shelves to approximate each triangular structure. In the figure, Bragg's law is observed that intensive reflections occur for $2 S(\cos \alpha) / \lambda$ being equal to positive integers. Moreover, it is interesting to find that the case with a larger incidence angle results in a more intensive Bragg reflection. In addition, it is noticeable that the secondary resonance $2 S(\cos \alpha) / \lambda=2$ is stronger than the primary resonance $2 S(\cos \alpha) / \lambda=1$. In addition, total Bragg reflections occur in the secondary resonances. 


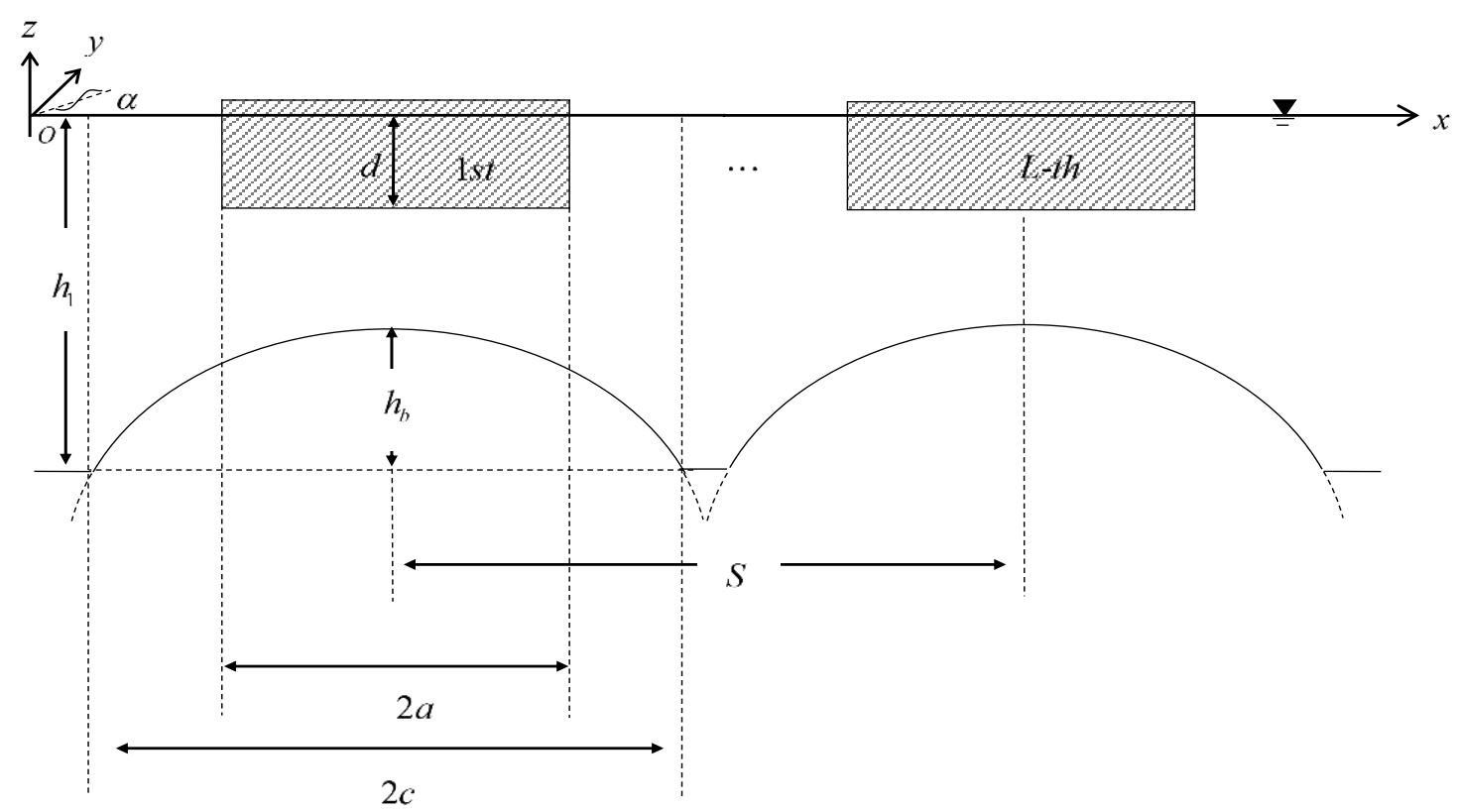

Figure 10. Schematic diagram of Bragg reflections by periodic rectangular surface-piercing structures over periodic parabolic breakwaters.

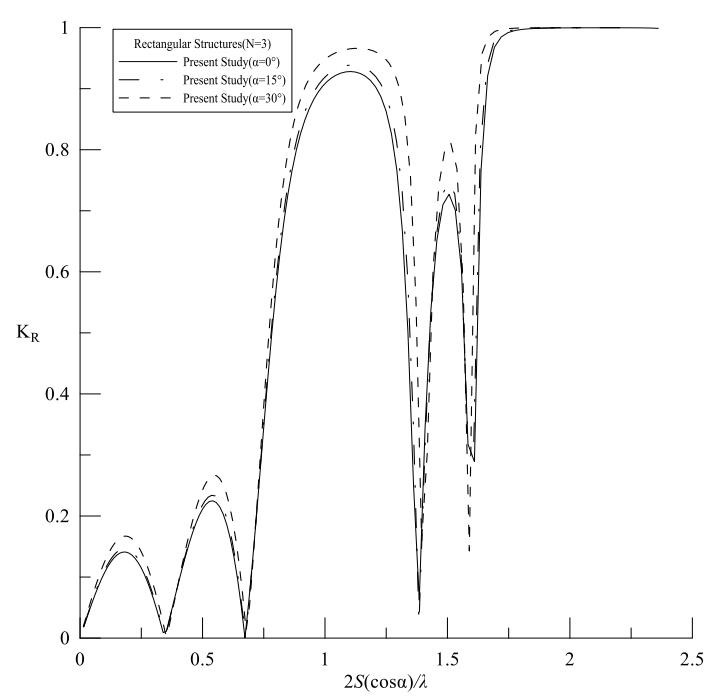

(a)

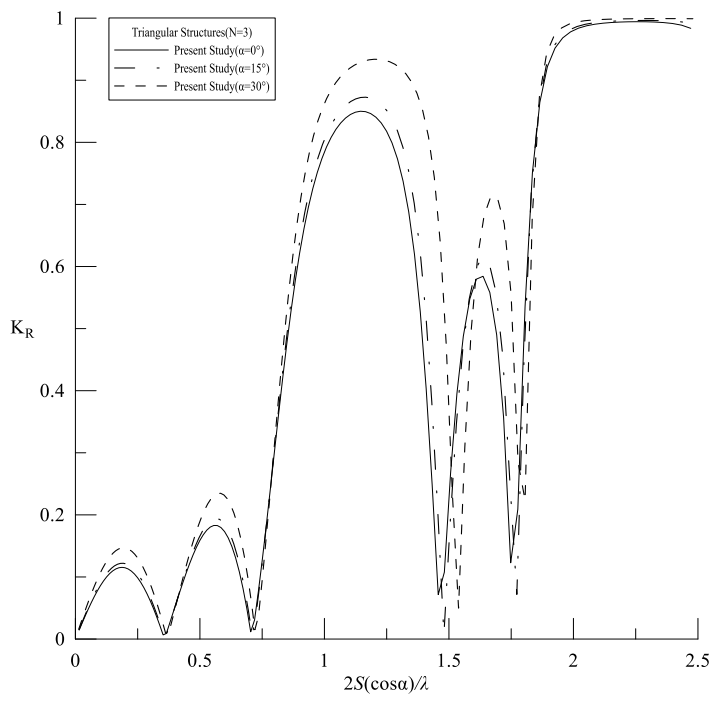

(b)

Figure 11. The reflection coefficients with different incidence angles for Bragg reflections by periodic (a) rectangular and (b) triangular surface-piercing structures over flat bottoms.

Before studying the combined Bragg reflections of periodic surface-piercing and submerged breakwaters, problems of Bragg reflections solely by three periodic parabolic breakwaters of different heights are considered. Here, we use 40 shelves to approximate each parabolic breakwater as before and in the following. As depicted in Figure 12a, the case of higher breakwaters results in a more intensive Bragg reflection, as expected. In addition, Figure 12b shows the Bragg reflections for different incidence angles, which also confirm Bragg's law when $2 S(\cos \alpha) / \lambda$ is equal to a positive integer. However, it is interesting to observe that a larger incidence angle results in a less intensive Bragg reflection and the primary resonance $2 S(\cos \alpha) / \lambda=1$ is stronger than the secondary resonance $2 S(\cos \alpha) / \lambda=2$, which are totally opposite to the situations of Bragg reflections caused solely by periodic surface-piercing structures. 


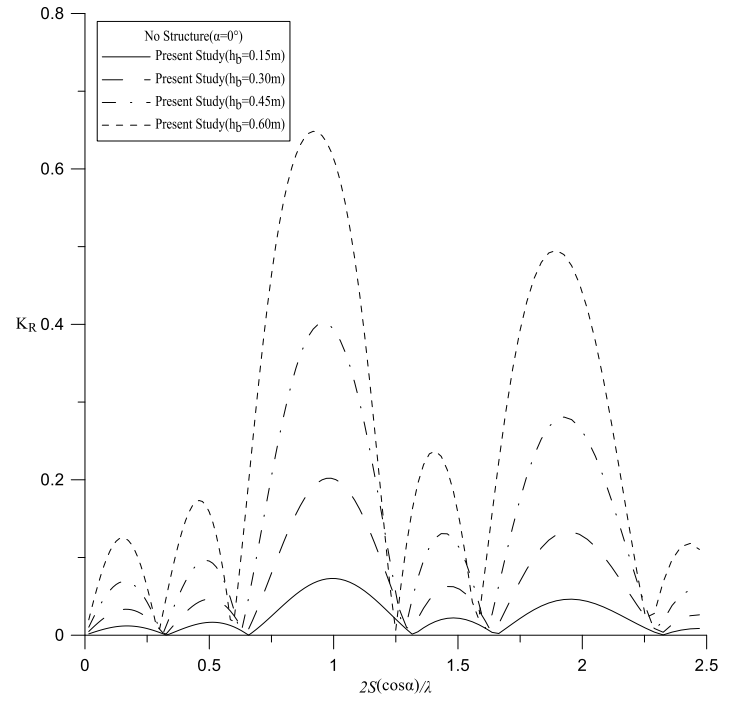

(a)

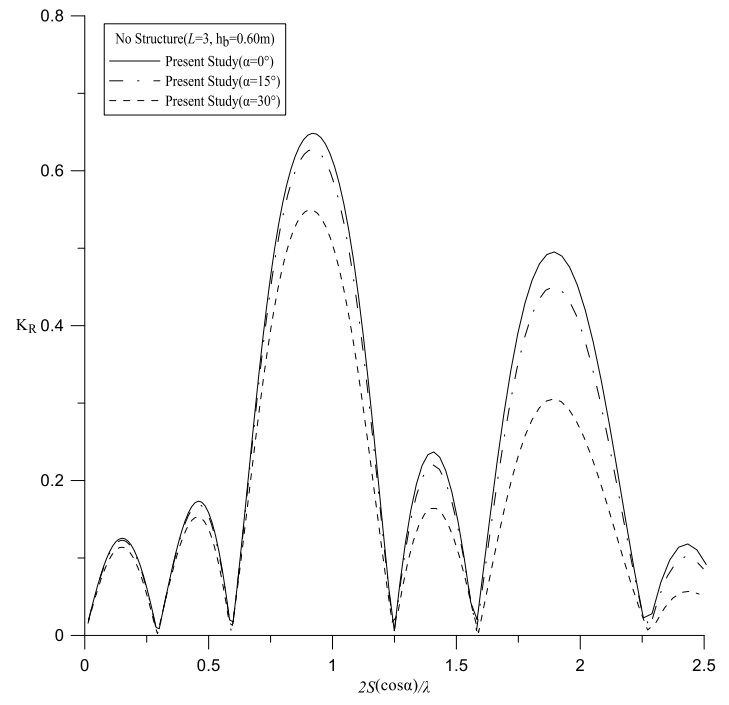

(b)

Figure 12. The reflection coefficients for Bragg reflections over periodic parabolic breakwaters of (a) different heights and (b) different incidence angles.

Then the combined Bragg reflections of periodic surface-piercing and submerged breakwaters are studied by setting different heights of the periodic parabolic breakwaters. As depicted in Figure 13, the EMM is applied to solve the problems of Bragg reflections of normal incident waves by three periodic rectangular surface-piercing structures over three periodic parabolic breakwaters. In the figure, it is clear that the case of higher breakwaters results in a stronger Bragg reflection, as expected. In addition, if the periodic breakwaters are high, total Bragg reflections occur for both the primary and secondary resonances.

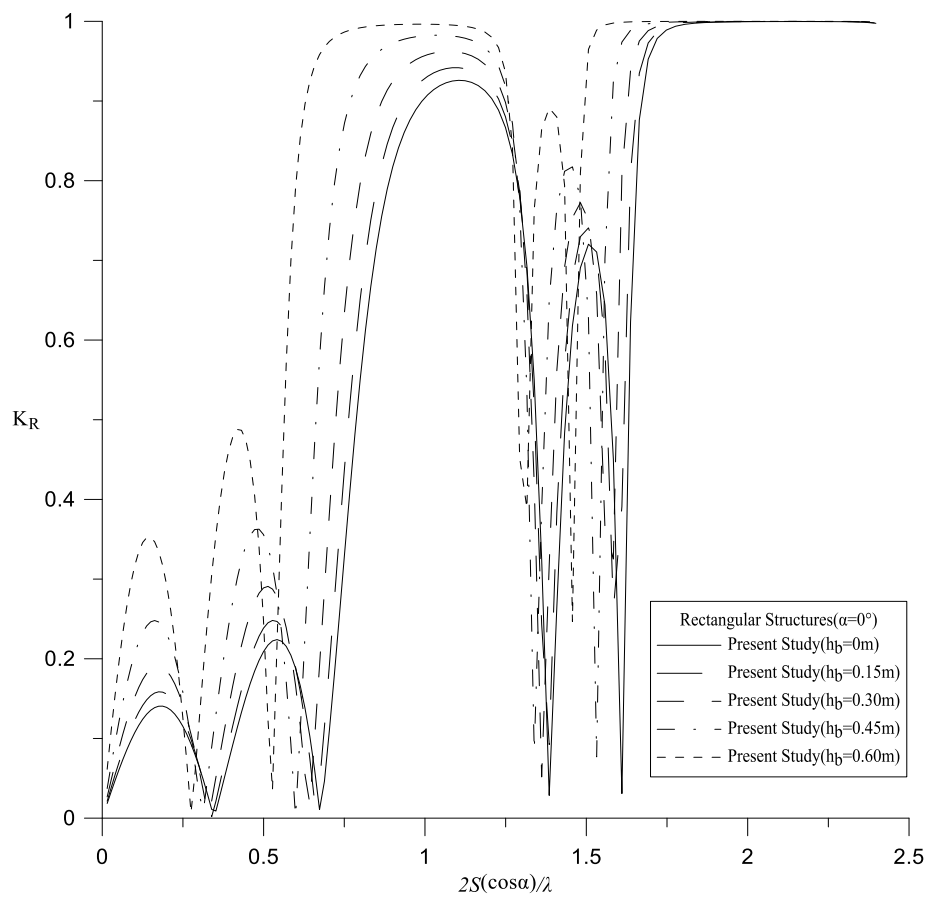

Figure 13. The reflection coefficients for Bragg reflections by periodic rectangular surface-piercing structures over periodic parabolic breakwaters of different heights. 
Then, the study with $h_{b}=0.6 \mathrm{~m}$ in Figure 13 is extended to oblique incidence angles, as depicted in Figure 14a, which also numerically confirms Bragg's law of oblique waves. As depicted in Figure 14b, the results are similar if the study is extended to five periodic rectangular surface-piercing structures over five periodic parabolic breakwaters.

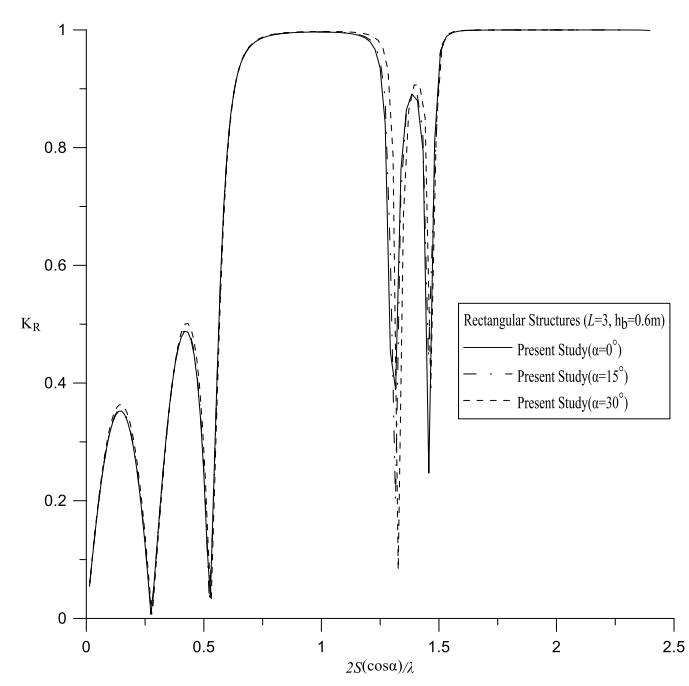

(a)

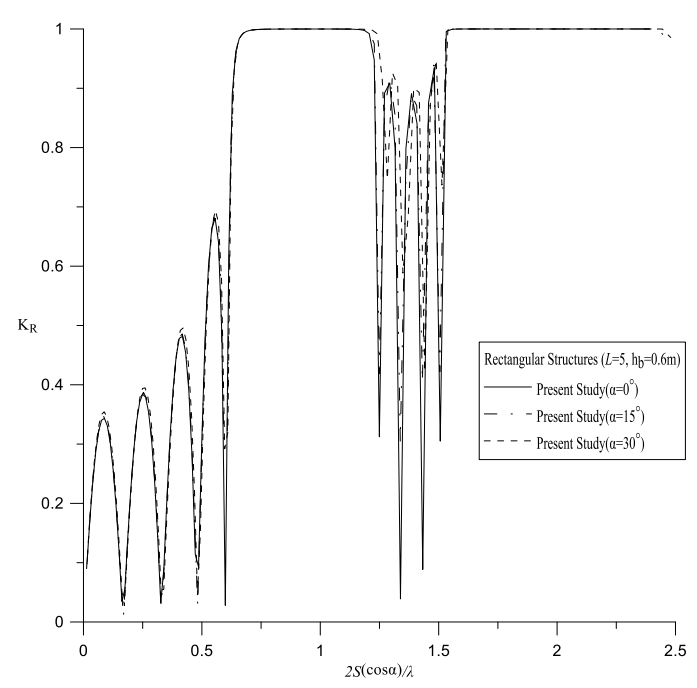

(b)

Figure 14. The reflection coefficients for Bragg reflections by periodic rectangular surface-piercing structures of different numbers (a) $L=3$ and (b) $L=5$ over periodic parabolic breakwaters.

Finally, if the surface-piercing structures are treated as floating rather than fixed, previous studies applied the EMM to problems involving a rectangular structure with surge [54,55], heave [56], and free motions [57]. Combing the proposed step approximation with these studies, the EMM can be applied to solve water-wave-scattering by a floating structure of different shapes over uneven bottoms. This is currently under investigation.

\section{Conclusions}

In this study, the combined Bragg reflections of oblique water waves by periodic surface-piercing and submerged breakwaters were solved using the eigenfunction matching method (EMM). In the solution procedure, the surface-piercing structures and bottom profiles are sliced into a number of shelves separated by abrupt steps. The solution on each shelf is composed of eigenfunctions with unknown coefficients. Then, a system of linear equations is obtained by applying the conservations of mass and momentum. The present method was validated under three problems of oblique wave scattering by a rectangular surface-piercing structure over a flat bottom, behind a parabolic breakwater, and Bragg reflection by periodic rectangular/triangular surface-piercing structures over a flat bottom. Then, the proposed method was applied to solve the Bragg reflections of oblique water waves by periodic surface-piercing structures over periodic bottoms. For oblique Bragg reflections by periodic surface-piercing structures, numerical results indicated that the case with a larger incidence angle results in a more intensive Bragg reflection and the secondary resonance is stronger than the primary resonance. However, the results are completely opposite for oblique Bragg reflections by periodic submerged breakwaters. In addition, Bragg's law of oblique waves was applied in the numerical experiments. Some theoretical and physical studies on the resonance intensity and incidence angle are required in future investigation.

Author Contributions: Conceptualization, I.-F.T. and C.-C.T.; methodology, C.-C.T.; software, C.-C.T.; validation, C.-S.Y. and C.-C.T.; formal analysis, C.-S.Y.; investigation, C.-S.Y.; resources, I.-F.T. and C.-C.T.; data curation, C.-S.Y.; writing —original draft preparation, I.-F.T. and C.-S.Y.; writing—review and editing, I.-F.T. and C.-C.T.; 
visualization, C.-S.Y.; supervision, I.-F.T. and C.-C.T.; project administration, I.-F.T. and C.-C.T.; funding acquisition, I.-F.T. and C.-C.T. All authors have read and agreed to the published version of the manuscript.

Funding: Ministry of Science and Technology, Taiwan: 107-2221-E-992-045-MY2.

Acknowledgments: The Ministry of Science and Technology of Taiwan is gratefully acknowledged for providing financial support to carry out the present work under the Grant No. MOST 107-2221-E-992-045-MY2.

Conflicts of Interest: The authors declare no conflicts of interest exist.

\section{References}

1. Belibassakis, K.; Athanassoulis, G. A coupled-mode technique for weakly nonlinear wave interaction with large floating structures lying over variable bathymetry regions. Appl. Ocean Res. 2006, 28, 59-76. [CrossRef]

2. Shih, R.-S. Experimental study on the performance characteristics of porous perpendicular pipe breakwaters. Ocean Eng. 2012, 50, 53-62. [CrossRef]

3. Chung, J.S. Motion of a floating structure in water of uniform depth. J. Hydronautics 1976, 10, 65-73. [CrossRef]

4. Kagemoto, H.; Fujino, M.; Murai, M. Theoretical and experimental predictions of the hydroelastic response of a very large floating structure in waves. Appl. Ocean Res. 1998, 20, 135-144. [CrossRef]

5. Mei, C.C.; Hara, T.; Naciri, M. Note on Bragg scattering of water waves by parallel bars on the seabed. J. Fluid Mech. 1988, 186, 147-162. [CrossRef]

6. Bailard, J.A.; DeVries, J.W.; Kirby, J.T. Considerations in using Bragg reflection for storm erosion protection. J. Waterw. Port Coast. Ocean Eng. 1992, 118, 62-74. [CrossRef]

7. Tsai, L.-H.; Wen, C.-C. Design of a series of submerged breakwaters for coastal protection against waves. China Ocean Eng. 2010, 24, 553-564.

8. Hsu, T.-W.; Lin, J.-F.; Hsiao, S.-C.; Ou, S.-H.; Babanin, A.V.; Wu, Y.-T. Wave reflection and vortex evolution in Bragg scattering in real fluids. Ocean Eng. 2014, 88, 508-519. [CrossRef]

9. Ouyang, H.-T.; Chen, K.-H.; Tsai, C.-M. Investigation on bragg reflection of surface water waves induced by a train of fixed floating pontoon breakwaters. Int. J. Nav. Archit. Ocean Eng. 2015, 7, 951-963. [CrossRef]

10. Ding, W.-W.; Zou, Z.-J.; Wu, J.-P.; Huang, B.-G. Investigation of surface-piercing fixed structures with different shapes for Bragg reflection of water waves. Int. J. Nav. Archit. Ocean Eng. 2019, 11, 819-827. [CrossRef]

11. Roseau, M. Asymptotic Wave Theory; North-Holland Pub. Co.: Amsterdam, NY, USA, 1976.

12. Berkhoff, J.C.W. Computation of combined refraction-diffraction. In Proceedings of the 13th International Conference on Coastal Engineering, Vancouver, BC, Canada, 10-14 July 1972; pp. 471-490.

13. Kirby, J.T. A general wave equation for waves over rippled beds. J. Fluid Mech. 1986, 162, 171-186. [CrossRef]

14. Chamberlain, P.G.; Porter, D. The modified mild-slope equation. J. Fluid Mech. 1995, 291, 393-407. [CrossRef]

15. Massel, S.R. Extended refraction-diffraction equation for surface waves. Coast. Eng. 1993, 19, 97-126. [CrossRef]

16. Porter, D.; Staziker, D.J. Extensions of the mild-slope equation. J. Fluid Mech. 1995, 300, 367-382. [CrossRef]

17. Athanassoulis, G.; Belibassakis, K. A consistent coupled-mode theory for the propagation of small-amplitude water waves over variable bathymetry regions. J. Fluid Mech. 1999, 389, 275-301. [CrossRef]

18. Belibassakis, K.; Athanassoulis, G. Extension of second-order Stokes theory to variable bathymetry. J. Fluid Mech. 2002, 464, 35-80. [CrossRef]

19. Belibassakis, K.A.; Athanassoulis, G.A.; Gerostathis, T.P. A Coupled-Mode Model for the Refraction-Diffraction of Linear Waves over Steep Three-Dimensional Bathymetry. Appl. Ocean Res. 2001, 23, 319-336. [CrossRef]

20. Belibassakis, K. A coupled-mode model for the scattering of water waves by shearing currents in variable bathymetry. J. Fluid Mech. 2007, 578, 413-434. [CrossRef]

21. Belibassakis, K.; Touboul, J. A nonlinear coupled-mode model for waves propagating in vertically sheared currents in variable bathymetry-Collinear waves and currents. Fluids 2019, 4, 61. [CrossRef]

22. Toledo, Y.; Agnon, Y. Three dimensional application of the complementary mild-slope equation. Coast. Eng. 2011, 58, 1-8. [CrossRef]

23. Belibassakis, K.; Touboul, J.; Laffitte, E.; Rey, V. A mild-slope system for bragg scattering of water waves by sinusoidal bathymetry in the presence of vertically sheared currents. J. Mar. Sci. Eng. 2019, 7, 9. [CrossRef] 
24. Suh, K.D.; Lee, C.; Park, W.S. Time-dependent equations for wave propagation on rapidly varying topography. Coast. Eng. 1997, 32, 91-117. [CrossRef]

25. Belibassakis, K.; Athanassoulis, G. A coupled-mode model for the hydroelastic analysis of large floating bodies over variable bathymetry regions. J. Fluid Mech. 2005, 531, 221-249. [CrossRef]

26. Porter, D.; Porter, R. Approximations to wave scattering by an ice sheet of variable thickness over undulating bed topography. J. Fluid Mech. 2004, 509, 145-179. [CrossRef]

27. Porter, D. The mild-slope equations: A unified theory. J. Fluid Mech. 2020, 887, A29. [CrossRef]

28. Takano, K. Effets d'un obstacle parallelepipedique sur la propagation de la houle. La Houille Blanche 1960, 15, 247-267. [CrossRef]

29. Kirby, J.T.; Dalrymple, R.A.; Seo, S.N. Propagation of obliquely incident water waves over a trench. Part 2. Currents flowing along the trench. J. Fluid Mech. 1987, 176, 95-116. [CrossRef]

30. Kirby, J.T.; Dalrymple, R.A. Propagation of obliquely incident water waves over a trench. J. Fluid Mech. 1983, 133, 47-63. [CrossRef]

31. Devillard, P.; Dunlop, F.; Souillard, B. Localization of gravity waves on a channel with a random bottom. J. Fluid Mech. 1988, 186, 521-538. [CrossRef]

32. O'Hare, T.J.; Davies, A.G. A comparison of two models for surface-wave propagation over rapidly varying topography. Appl. Ocean Res. 1993, 15,1-11. [CrossRef]

33. O'Hare, T.J.; Davies, A.G. A new model for surface wave propagation over undulating topography. Coast. Eng. 1992, 18, 251-266. [CrossRef]

34. Tsai, C.-C.; Lin, Y.-T.; Hsu, T.-W. On step approximation of water-wave scattering over steep or undulated slope. Int. J. Offshore Polar Eng. 2014, 24, 98-105.

35. Tsai, C.C.; Hsu, T.-W.; Lin, Y.-T. On Step Approximation for Roseau's Analytical Solution of Water Waves. Math. Probl. Eng. 2011, 2011. [CrossRef]

36. Tsai, C.-C.; Lin, Y.-T.; Chang, J.-Y.; Hsu, T.-W. A coupled-mode study on weakly viscous Bragg scattering of surface gravity waves. Ocean Eng. 2016, 122, 136-144. [CrossRef]

37. Tsai, C.C.; Lin, Y.-T.; Hsu, T.-W. On the weak viscous effect of the reflection and transmission over an arbitrary topography. Phys. Fluids 2013, 25, 043103-043121. [CrossRef]

38. Tsai, C.-C.; Lin, Y.-T.; Hsu, T.-W. Propagating of obliquely incident, weakly viscous waves over variable bathymetry. J. Coast. Res. 2016, 32, 974-982. [CrossRef]

39. Tsai, C.-C.; Tai, W.; Hsu, T.-W.; Hsiao, S.-C. Step approximation of water wave scattering caused by tension-leg structures over uneven bottoms. Ocean Eng. 2018, 166, 208-225. [CrossRef]

40. Liu, X.; Wang, X.; Xu, S. A DMM-EMM-RSM hybrid technique on two-dimensional frequency-domain hydroelasticity of floating structures over variable bathymetry. Ocean Eng. 2020, 201, 107135. [CrossRef]

41. Tsai, C.-C.; Chou, W.-R. Comparison between consistent coupled-mode system and eigenfunction matching method for solving water wave scattering. J. Mar. Sci. Tech. Taiw. 2015, 23, 870-881. [CrossRef]

42. Katō, J.; Hagino, S.; Uekita, Y. Damping effect of floating breakwater to which anti-rolling system is applied. In Proceedings of the Tenth Conference Coastal Engineering, Tokyo, Japan, September 1966; pp. 1068-1078.

43. Bai, K.J. Diffraction of oblique waves by an infinite cylinder. J. Fluid Mech. 1975, 68, 513-535. [CrossRef]

44. Kanoria, M.; Dolai, D.P.; Mandal, B.N. Water-wave Scattering by Thick Vertical Barriers. J. Eng. Math. 1999, 35, 361-384. [CrossRef]

45. Söylemez, M.; Gören, Ö. Diffraction of oblique waves by thick rectangular barriers. Appl. Ocean Res. 2003, 25, 345-353. [CrossRef]

46. Garrison, C.J. Interaction of oblique waves with an infinite cylinder. Appl. Ocean Res. 1984, 6, 4-15. [CrossRef]

47. Manisha; Kaligatla, R.B.; Sahoo, T. Effect of bottom undulation for mitigating wave-induced forces on a floating bridge. Wave Motion 2019, 89, 166-184. [CrossRef]

48. Bragg, W.H.; Bragg, W.L. The reflection of X-rays by crystals. Proc. R. Soc. Lond. Ser. A 1913, 88, $428-438$. [CrossRef]

49. Mei, C.C. Resonant reflection of surface water waves by periodic sandbars. J. Fluid Mech. 1985, 152, 315-335. [CrossRef]

50. Dalrymple, R.A.; Kirby, J.T. Water waves over ripples. J. Waterw. Port Coast. Ocean Eng. 1986, 112, 309-319. [CrossRef]

51. Zettl, A. Sturm-Liouville Theory; American Mathematical Society: Rhode Island, RI, USA, 2005. 
52. Li, X.S. An overview of SuperLU: Algorithms, implementation, and user interface. ACM Trans. Math. Softw. 2005, 31, 302-325. [CrossRef]

53. Lebreton, J.; Margnac, M. Traitement sur ordinateur de quelques problèmes concernant l'action de la houle sur les corps flottants en théorie bidimensionelle. In Bulletin du Centre de Recherches et D'Essais de Chatou; Chatou: Yvelines, France, 1966; pp. 3-43.

54. Lee, C.-P.; Lee, J.-F. Wave-induced surge motion of a tension leg structure. Ocean Eng. 1993, 20, $171-186$. [CrossRef]

55. Lee, C.-P. Dragged surge motion of a tension leg structure. Ocean Eng. 1994, 21, 311-328. [CrossRef]

56. Lee, J.-F. On the heave radiation of a rectangular structure. Ocean Eng. 1995, 22, 19-34. [CrossRef]

57. Zheng, Y.H.; Shen, Y.M.; You, Y.G.; Wu, B.J.; Jie, D.S. On the radiation and diffraction of water waves by a rectangular structure with a sidewall. Ocean Eng. 2004, 31, 2087-2104. [CrossRef]

(C) 2020 by the authors. Licensee MDPI, Basel, Switzerland. This article is an open access article distributed under the terms and conditions of the Creative Commons Attribution (CC BY) license (http://creativecommons.org/licenses/by/4.0/). 